Gut, 1962, 3, 333

\title{
The use of the d-xylose excretion test in children
}

\author{
PETER A. CLARK \\ From the University of the West Indies, Kingston, Jamaica
}

EDITORIAL SYNOPSIS The results of the d-xylose excretion test modified for use in children have indicated its value in the differentiation of coeliac disease and fibrocystic disease of the pancreas.

In recent years, the pentose, $d$-xylose, has been widely used in the investigation of small bowel function. Most of these tests of xylose absorption depend on the administration of an oral dose of the sugar, followed by an estimation of the xylose levels of the blood or urine. Disease of the upper part of the small bowel has been found to impair xylose absorption; low blood and urine values have been found in tropical sprue and adult coeliac disease (idopathic steatorrhoea) (Benson, Culver, Ragland, Jones, Drummey, and Bougas, 1957; Butterworth, Perez-Santiago, Martinez de Jesus, and Santini, 1959). Disease of the distal part of the small bowel does not usually lessen the absorption of xylose (Fowler and Cooke, 1960). About $65 \%$ of the ingested dose of xylose is absorbed from the bowel: it is thought that some d-xylose is metabolized (Christiansen, Kirsner, and Ablaza, 1959). In adults, various authors have found that approximately $25 \%$ of the dose of xylose is excreted in the urine during the five hours following ingestion (Table II). Gardner and Perez Santiago (1956) found that the bulk of xylose excretion occurred in this period, little being excreted subsequently.

In children who fail to thrive and who have large offensive stools, the differential diagnosis often lies between coeliac disease and fibrocystic disease of the pancreas. The jejunal mucosa in fibrocystic disease is normal whereas that in coeliac disease is atrophic (Shiner, 1960) and impairment of xylose absorption might be expected in the latter. In the present work the xylose excretion test has been used in an attempt to assist in the differential diagnosis between coeliac disease and fibrocystic disease of the pancreas.

\section{SUBJECTS}

In an attempt to establish a normal range of xylose excretion, the test was used on $\mathbf{4 0}$ children who had been admitted to hospital with non-alimentary symptoms. Most of these children were convalescent and included, among others, patients with respira- tory infections, skin diseases, rheumatic heart disease, and patients with head injury who had been admitted for observation. Care was taken to exclude patients with renal symptoms which might have impaired xylose excretion. None of these patients were particularly ill at the time of the test.

The test was also used on 24 occasions on patients who were thought to have alimentary disease. The provisional diagnosis of these cases included coeliac disease, fibrocystic disease of the pancreas, Crohn's disease, and ulcerative colitis. In addition to the xylose test, other investigations were done on most of these patients. These included estimation of duodenal and faecal trypsin and of a five-day fat balance.

\section{METHOD}

The subject was fasted overnight. On the following morning, the bladder was emptied (this urine being discarded) and a dose of d-xylose given in water. This dose was calculated on the basis of $15 \mathrm{~g}$. of xylose per square metre of body surface area. The child was encouraged to drink water on two further occasions to ensure a good flow of urine. The urine was collected for a period of five hours following administration of the dose. The nursing staff was asked to record the times at which urine was voided. This information may be useful in evaluating the results if a child is unable to empty his bladder at the end of the test.

In very small children in whom urine collection might have been difficult, no attempt was made to collect the urine directly. The child was allowed to pass its urine into napkins which were put in a bucket. The xylose present in the napkins was then extracted with 5 litres of tap water. The small volume of urine passed by these babies was ignored when correcting for the volume of tap water used for extraction. Any test in which a specimen was contaminated by faeces was abandoned. The xylose content of the urine was then estimated by the method of Roe and Rice (1948) slightly modified.

The modification consisted of increasing the time and temperature of incubation from 10 minutes at $70^{\circ} \mathrm{C}$. to 15 minutes at $80^{\circ} \mathrm{C}$., and the time allowed for colour development was increased from 70 minutes to 90 minutes. 
This procedure has had the effect of increasing considerably the sensitivity of the method with little loss of specificity. Using this modification, the mean recovery of xylose added to urine has been found to be $98 \%$.

While this modification has been found to be satisfactory with urine, it has not yet been used for the estimation of xylose in tissue extracts.

The results were expressed as a percentage of the oral dose.

\section{RESULTS}

The results determined in the present series are shown in Fig. 1 and Table $I$.

The normal range of xylose excretion determined in the present series is similar to the normal ranges found in adults by various authors (Table II). There is a wide range of xylose excretion in normal children,

TABLE I

FIVE-HOUR URINARY EXCRETION OF D-XYLOSE ( $\%$ OF ORAL DOSE)

\begin{tabular}{|c|c|c|}
\hline Diagnosis & No. of Cases & Range (\%) \\
\hline Normal subjects & 40 & $\begin{array}{c}10-41 \\
\text { (Mean 24.2, } \\
\text { S.E. 7·0) }\end{array}$ \\
\hline Fibrocystic disease of the pancreas & 6 & $24-36$ \\
\hline Coeliac disease (untreated) & 5 & $2-12$ \\
\hline Coeliac disease (treated) & 4 & $5-23$ \\
\hline ‘Coeliac disease?’ later disproved & 2 & 21-25 \\
\hline Crohn's disease & $\overline{1}$ & 21 \\
\hline Ulcerative colitis & 1 & 13 \\
\hline Gastroenteritis & 1 & 13 \\
\hline Miscellaneous malabsorptions & 4 & $10-18$ \\
\hline
\end{tabular}

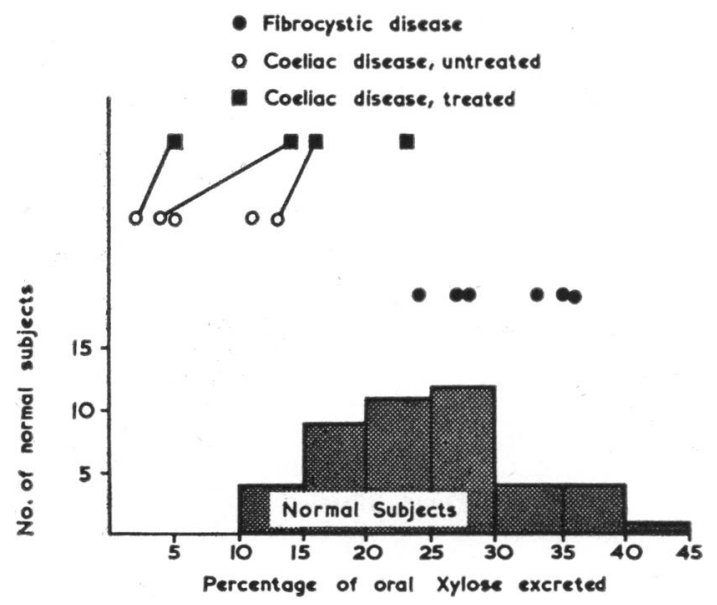

FIG. 1. Five-hour urinary excretion of xylose in six cases of fibrocystic disease of the pancreas; five cases of coeliac disease before treatment; four cases of coeliac disease after treatment. This diagram also demonstrates the distribution of xylose excretion levels in 40 normal subjects. similar to the findings in the adult. Four patients, without apparent alimentary disease, excreted at a single test amounts of xylose which were lower than expected. One of these patients was being investigated after a convulsion ( $10 \%$ excretion); the other three patients had had lobar pneumonia $(13 \%, 13 \%, 14 \%)$. Unfortunately it was not possible to repeat the test in any of these cases.

A marked difference of xylose excretion was found between cases of coeliac disease and those of fibrocystic disease of the pancreas. Five cases of coeliac disease excreted low amounts of xylose. Six cases of fibrocystic disease excreted amounts of xylose which were higher than the mean of normal subjects. Although the numbers of these cases are small the difference is significant. A short description will be given of two cases which were originally diagnosed and treated as coeliac disease and were later shown to be fibrocystic disease of the pancreas.

EXAMPLE Two patients, a boy aged 9 years and his sister aged 27 months, had been diagnosed as cases of coeliac disease and treated with a gluten-free diet without improvement. Xylose tests showed excretion of $33 \%$ and $35 \%$ respectively. These values were much higher than would have been expected in coeliac disease. Subsequent investigation showed low values for faecal and duodenal trypsin and a final diagnosis of fibrocystic disease of the pancreas was made.

In three cases of coeliac disease it has been possible to repeat the xylose test after treatment with a gluten-free diet (Fig. 1). In two of these cases there was a marked rise in xylose excretion following some weeks of treatment. The third case, a child aged 18 months, had only been treated for a few days at the time of the second test and only a small increase in excretion was found.

This test has been found to be simple and reproducible. At times there have been difficulties in the administration of xylose and the collection of urine: it is probably advisable to repeat the test when unexpectedly low results occur. A small number of children have vomited the xylose or have had diarrhoea. Diarrhoea has been reported in adult subjects (Benson et al., 1957). No other side-effects have been noticed in the present series. The method of collecting urine in small children has proved satisfactory. A small variation in the duration of urine collection is usually unimportant.

\section{DISCUSSION}

The xylose excretion test appears to be a most useful screening method in the investigation of malabsorption in children. It is tolerated well by most patients 
TABLE II

URINARY XYLOSE EXCRETION IN ADULTS

\begin{tabular}{|c|c|c|c|c|c|}
\hline \multirow[t]{3}{*}{ Author } & \multirow[t]{3}{*}{ No. of Cases } & \multicolumn{4}{|c|}{ Urinary Xylose Excretion after $25 \mathrm{~g}$. Xylose } \\
\hline & & \multicolumn{2}{|c|}{ Mean } & \multicolumn{2}{|l|}{ Range } \\
\hline & & g. & $\%$ & g. & $\%$ \\
\hline $\begin{array}{l}\text { Fourman (1948) } \\
\text { Benson et al. (1957) } \\
\text { Christiansen et al. (1959) } \\
\text { Fowler and Cooke (1960) }\end{array}$ & $\begin{array}{r}4 \\
24 \\
10 \\
35\end{array}$ & $\begin{array}{l}6 \cdot 1 \\
6 \cdot 5 \\
6 \cdot 8 \\
7 \cdot 2\end{array}$ & $\begin{array}{l}24 \\
26 \\
27 \\
29\end{array}$ & $\begin{array}{l}4 \cdot 3-6 \cdot 7 \\
4 \cdot 1-8 \cdot 2 \\
5 \cdot 6-8 \cdot 2 \\
4 \cdot 2-11 \cdot 5\end{array}$ & $\begin{array}{l}17-26 \\
16-33 \\
22-33 \\
17-46\end{array}$ \\
\hline
\end{tabular}

and is a simple procedure for both nursing and laboratory staff.

Although the xylose tolerance test has been used in children by Wolfish, Hildick-Smith, Ebbs, Connell, and Sass-Kortsak (1955), the xylose excretion test seems to be preferable. Benson et al. (1957) found that the results of the tolerance test were not always useful as there was some overlap between normal and malabsorptive subjects. The tolerance test, like the glucose tolerance test, has the further disadvantage of requiring a series of blood specimens which is undesirable in small children. The estimation of xylose in blood is more complicated than in urine.

The test is of particular value in making the differential diagnosis between coeliac disease and fibrocystic disease of the pancreas. Low values of xylose excretion are found in coeliac disease just as in adult gluten-induced enteropathy. It is interesting that the cases of fibrocystic disease have a xylose excretion above the normal mean. Hepatic lesions in association with fibrocystic disease of the pancreas have been cited by Boyd (1958). It is possible that poor hepatic function may lessen the portion of absorbed xylose which is metabolized and thereby increase the amount excreted unchanged in the urine.

It is likely that some cases of gastro-enteritis and ulcerative colitis excrete low amounts of xylose.
I wish to thank Professor A. V. Neale and the consultant staff of Bristol Royal Hospital for Sick Children for permission to study their cases.

My thanks are also due to Dr. G. K. McGowan, consultant chemical pathologist, United Bristol Hospitals, in whose department most of this work was done.

\section{REFERENCES}

Benson, J. A., Culver, P. J., Ragland, S., Jones, C. M., Drummey, G. D., and Bougas, E. (1957). The D-xylose absorption test in malabsorption syndromes. New Engl. J. Med., 256, 335-339.

Boyd, W. (1958). Pathology for the Physician. 6th ed., p. 457-458. Lea and Febiger, Philadelphia.

Butterworth, C. E., Perez-Santiago, E., Martinez de Jesus, J., and Santini, R. (1959). Studies on the oral and parenteral administration of D (+) xylose. New Engl. J. Med., 261, 157-164.

Christiansen, P. A., Kirsner, J. B., and Ablaza, J. (1959). D-Xylose and its use in the diagnosis of malabsorptive states. Amer. $J$. Med., 27, 443-453.

Fourman, L. P. R. (1948). The absorption of xylose in steatorrhoea. Clin. Sci., 6, 289-294.

Fowler, D., and Cooke, W. T. (1960). Diagnostic significance of D-xylose excretion test. Gut, 1, 67-70.

Gardner, F. H., and Perez Santiago, E. (1956). Oral absorption tolerance tests in tropical sprue. Arch. intern. Med., 98, 467-474.

Roe, J. H., and Rice, E. W. (1948). A photometric method for the determination of free pentoses in animal tissues. J. biol. Chem., 173, 507-512.

Shiner, M. (1960). Coeliac disease: histopathological findings in the small intestinal mucosa studied by a peroral biopsy technique. Gut, 1, 48-54.

Wolfish, M. G., Hildick-Smith, G. J., Ebbs, J. H., Connell, M. L. and Sass-Kortsak, A. (1955). The d-xylose tolerance test: A measure of intestinal absorption in normal and dystrophic infants. Amer. J. Dis. Child., 90, 609. 